\title{
MARKET STRUCTURE ANALYSIS WITH HERFINDAHL-HIRCHMAN INDEX AND LAURAÉUS-KAIVO-OJA INDICES IN THE GLOBAL COBOTICS MARKETS
}

\author{
Theresa Lauraéus ${ }^{1,2}$, Jari Kaivo-oja ${ }^{1,2}$, Mikkel S. Knudsen ${ }^{1,2}$ \& Kimmo Kuokkanen ${ }^{3}$ \\ ${ }^{1}$ Kazimiero Simonavičiaus University, Vilnius, Lithuania, \\ ${ }^{2}$ Finland Futures Research Centre, Turku School of Economics, University of Turku, Turku, Finland \\ jari.kaivo-oja@utu.fi,theresa.lauraeus@aalto.fi,Mikkel.knudsen@utu.fi \\ ${ }^{3}$ Statzon Ltd, Lahti, Finland kimmo@statzon.com
}

\begin{abstract}
Research purpose. The study is focused on the expected market dynamics of global cobotics markets. This study investigates the current market structure of the global cobotics market. The scientific aim of the research is to report the first data-based market structure analysis of the global cobotics market with the HHI index and with the LKI index analysis. With analysis we are able to show the diversification rate of the global cobotics market.

Design / Methodology / Approach. The methodology is based on conventional statistical index theory and statistics. The methodology is the calculation of the Herfindahl-Hirchman Index and the Lauraéus-Kaivo-oja Index. The authors compare the results of these two methodologies.

Findings. The Herfindahl-Hirschman Index (HHI) and the Lauraéus-Kaivo-oja Index are statistical measures of market concentration, and they can be used to determine market competitiveness. This paper demonstrates novel data analytics possibilities of new market data collected by the Statzon, Ltd with various comparative analytical results and findings. By our analyses we can help multiple industrial stakeholders make faster decisions and better strategic plans with the easiest and fastest access to accurate, reliable, and up-to-date cobotics industry statistics, forecasts, and insights. The finding is that this study reveals the current market structure of global cobotics. It is a novel finding and result.

Originality / Value / Practical implications. This paper demonstrates the novel and exciting possibilities of transparent index calculation tools. The authors provide original results. Authors underline that extra value added to stakeholders and customers will be provided by joint data pooling strategy of various data sources, which is a key approach of this paper. Real-time market structure analyses create reliable and knowledge-based information for decision-makers and stakeholders of the global cobotics industry.
\end{abstract}

Keywords: Market trends; Market structure of global cobotics market; Herfindahl-Hirschman Index (HHI); Lauraéus-Kaivo-oja Index (LKI); Market data analytics.

JEL codes: C13, C53, C63, D52, G28.

\section{Introduction}

This paper studies the current market structure of the global cobotics market and the expected market dynamics of global cobotics markets. We show the first data-based market structure analysis of the global cobotics market with the HHI and the LKI analyses. We aim to show the diversification rate of the global cobotics market with these two analysis methods.

Definition of the concept of cobots: Collaborative robots (cobots) are robots, which enable direct interaction between humans and robots. Cobots promote human-robot collaboration (HRC) and differs from the traditional industrial robot, which separates human-robot interaction (HRI) by safety cages (Gervasi et al., 2020). 
Collaborative robots differ from industrial robots in several ways, such as (1) the elimination of a safety fence while working alongside humans, (2) simplified programming and reduced setup time, (3) integration of auto-speed reduction and distance monitoring or proximity sensors, and (4) ability to reduce motor power and force during application to avoid harm to a worker (Knudsen \& Kaivo-oja, 2020; Stieber 2015).

Compared to traditional industrial robots, cobots are usually lighter, more mobile, cheaper, and easier to reprogram. Experts note that this makes them especially suitable for companies with many productions, variants, small lot sizes, and fluctuating production volumes (Knudsen \& Kaivo-oja, 2020; Kopp et al., 2021), for example, SMEs. These features also make them ideally suited for the modern manufacturing paradigms of Industry 4.0, intelligent manufacturing, and mass customisation (Knudsen \& Kaivo-oja, 2020).

The recent experience of the COVID-19 pandemic has only leveraged the importance of the industry. Robots do not get the coronavirus (Brakman et al., 2021), and the magazine The Economist reports of a "surge in demand for material handling equipment and "collaborative robots", designed to interact with people" (The Economist, 2021). They further note that while cobots aid in keeping the social distance, the technology will be a boon to post-pandemic productivity.

We will introduce the classical Herfindahl-Hirschman Index (HHI index). Based on that, we will show the development of a novel Lauraéus-Kaivo-oja indicator, which will be a more easily comprehensible analysis tool than the conventional HHI index.

Lauraeus-Kaivo-oja index can be defined as an analysis tool for market competition situation and measurement of market concentration.

With the HHI index and the LKI index we have analysed new transparent ways to perform the competition and market structure analyses (Lauraéus \& Kaivo-oja, 2017). The HHI index and the LKI index are suitable for analysing the dynamics of competition and emerging trends and structural changes of global innovation ecosystems (Kaivo-oja \&Lauraeus 2017).

This paper's research problem is what is the global cobot market competition situation in 2020. Which direction is the global cobot market shifting? How to calculate the LKI index? How do the HHI and the LKI indices differ? The research cap: There is little research about cobot market and even less research about cobot market competition situation analysis. This paper analyses and compares the HerfindahlHirschman Index (HHI index) and the novel Lauraéus-Kaivo-oja index and analyses results. The LKI index is calculated from the $\mathrm{HHI}$ index.

\section{Literature Review}

\section{Collaborative Robots (Cobots) Market}

Collaborative robots (also known as cobots) are designed to work alongside humans with precision, strength, and speed to achieve greater efficiency in production. Using robots to assist humans can help to significantly reduce the workload of human workers and relieve them of monotonous, repetitive tasks. Being an emerging automation technology, collaborative robots complement the existing market of industrial robotics. The total cost of ownership of factory automation solutions, especially for small and medium-sized enterprises (SMEs), can be significantly reduced with the adoption of cobots.

Collaborative robotics (cobots) has become one of the most talked-about sectors of the robotics markets (Knudsen \& Kaivo-oja, 2020). Cobots differ from traditional robots by enabling direct human-robot collaboration (HRC), whereas traditional industrial robots physically separate humans and machines through extensive security measures. The return of research and market interest in cobotics is consistent with emerging subfields of research that recognise the unique skillsets of humans for perception and adaption (Goldberg, 2019). Therefore, cobot technology promises to leverage the flexibility and adaptive capabilities of humans with the strengths and endurance of machines.

For many industrial plant contexts, cobots also have significant benefits in comparison compared to traditional industrial robots. Cobots are generally cheaper, more mobile, easier to program, and more 
efficient in configurability for new production process tasks. Therefore, they are well suited for new Industry 4.0 digital paradigms with more attention towards flexibility, customisation, smaller sizes, and faster speed of delivery to market.

\section{The Herfindahl-Hirschman Index (HHI Index)}

Definition of the Herfindahl-Hirschman Index, HHI index: The term "HHI" means the HerfindahlHirschman Index, a commonly accepted measurement of market concentration. The HHI index is defined as the sum of the squares of the market shares of the firms within the industry. The result is proportional to the average market share, weighted by market share. The Herfindahl-Hirschman Index, HHI, is a measure of the size of firms in relation to the industry and an indicator of the amount of competition among them (Herfindahl 1950, Hirschman 1964, Adams 2017).

The calculation of the HHI differs from the standard Concentration Ratio in that it squares each market share value, which places higher importance on those top companies that have a larger market share.

The HHI is calculated by taking the market share of each firm in the industry, squaring them, and totalling up the result (Rhoades 1993, 188).

The HHI accounts for the number of firms in a market, as well as concentration, by incorporating the relative size (market share, MS) of all firms in a market. The HHI is calculated by squaring the market share of each firm competing in the market and then totalling up the resulting numbers (Herfindahl 1950, Hirschman 1964, Adams 2017).

Next, we will present the calculation and every step from the Herfindahl-Hirschman Index (HHI) to the Lauraéus-Kaivo-oja Index, the LKI (Lauraéus \& Kaivo-oja, 2017). We aim to provide a novel method to analyse global cobots markets. This kind of novel index is useful for various fields of research policy planning and research (Lauraéus \& Kaivo-oja 2017). Lauraéus-Kaivo-oja Index (LKI) is an analysing tool for the measurement of market concentration.

Increases in the HHI or the LKI indices generally indicate that the market situation shifts to the monopoly direction, which means the increase of market power for leading companies.

Decreases in the HHI or the LKI indices indicate shifts to the nearly competition direction and an increase in competition. (Lauraéus \& Kaivo-oja 2017, Herfindahl 1950, Hirschman 1964, Adams 2017).

The difference between the HHI and the LKI indices measurements is that the HHI gives more weight to larger firms. The HHI takes into account the relative size distribution of firms in a market. The Herfindahl-Hirschman Index increases both as the number of firms in the market decreases and the disparity in size between those firms increases (Herfindahl 1950, Hirschman 1964, Adams 2017).

\section{Research methodology}

The methodology is based on conventional statistical index theory and statistics. The methodology is the calculation of the Herfindahl-Hirchman Index and the Lauraéus-Kaivo-oja Index. The authors compare the results of these two methodologies on global cobots market data.

\section{The Calculation of the Lauraéus-Kaivo-oja Index}

The calculation of the LKI index creation is based on the Herfindahl-Hirschman Index demonstrated, using a mathematic formula, $\mathrm{HHI}$, as:

$$
\mathrm{HHI}=\mathrm{s} 1^{\wedge} 2+\mathrm{s} 2^{\wedge} 2+\mathrm{s} 3^{\wedge} 2+\ldots+\mathrm{sn} n^{\wedge},
$$

which can be written using a mathematic formula:

$$
\mathrm{HHI}=\sum_{1}^{k}\left(\frac{100 * n_{i}}{N}\right)^{2},
$$

$\mathrm{k}=$ the number of different classes in the sample 
$\mathrm{N}=$ whole quantity of the sample,

$\bar{n}=$ average value of the sample classes,

$n_{i}=$ single sample

where the whole quantity of the sample $=\mathrm{N}$, the number of different classes in the sample $=\mathrm{k}$, and the average value of the sample classes $=\bar{n}$. We do not need $100^{2}$ for anything, so we can remove it. We can write the percentages as well with the decimals of $0.01-0.99$, which means the same as $1 \%-99 \%$. Thus, we will not have a problem with values $0-10000$, which are more difficult to understand than the normal percentage value.

Thus, we re-mark the index hhi, which means HHI without $100^{2}$.

$$
\mathrm{HHI}=100^{2} * \mathrm{hhi}=10000 * \mathrm{hhi}
$$

Thus, we will take out the $100^{2}$, and we will change the HHI formula to the new name "hhi", which is:

$$
\text { hhi }=\sum_{1}^{k}\left(\frac{n_{i}}{N}\right)^{2}
$$

which means the same as:

$$
\text { hhi }=\frac{1}{N^{2}} \sum_{1}^{k}\left(n_{i}\right)^{2}
$$

$\delta^{2}=$ diagonal standard deviation,

$\mathrm{k}=$ number of classes of the sample

$\mathrm{N}=$ Sample,

$\bar{n}=$ average value of the sample classes,

$\bar{n}^{2}=$ diagonal average value of the sample classes.

On the other hand, the whole quantity of the sample is $=\mathrm{N}$, Which is the same thing as the number of different classes in the sample. The total sum in the sample classes is:

$$
\mathrm{N}=\mathrm{k} * \bar{n}=\mathrm{k} \bar{n}
$$

Thus, we can write the "hhi" formula as

$$
\text { hhi }=\frac{1}{\mathrm{k} \bar{n}^{2}} \sum_{1}^{k}\left(n_{i}\right)^{2}
$$

Then, the same "hhi" index can be presented as

$$
\text { hhi }=\frac{\delta^{2}}{\mathrm{kn}^{2}}+\frac{1}{k}
$$

when $\frac{1}{k}$ means 1 over $\mathrm{k}$ number of classes of the sample. We do not need that $\frac{1}{k}$ for anything. Otherwise, we will have a big distorted picture of key trends. If one has different numbers of classes in the sample, one cannot compare the different classes with each other or distort the analytical analysis.

For example, a statistical sample consists of 34 classes of goods $\left(\frac{1}{k}=\frac{1}{34}=0,029=2,9 \%\right)$ and 11 classes of services $\left(\frac{1}{k}=\frac{1}{11}=0.09=9 \%\right)$. That analysis situation means, the fewer the classes, the bigger the per 
cent number added to the "hhi" will be. Thus, let us ask why this kind of percentage number should be added to the index? We can remove $\frac{1}{k}$, and thus, we will have a better, more informative, and more relevant trend curve.

$$
\mathrm{LKI}=\frac{\delta^{2}}{\mathrm{k} \bar{n}^{2}}
$$

The completely divided material, where all of the numbers of the samples are in one class $\frac{1}{k}=\frac{1}{1}=1$.

The maximal diagonal standard deviation is $\delta^{2}=(\mathrm{k}-1) \bar{n}^{2}$. That is why the divisor must be $(\mathrm{k}-1)$.

The wrong divider is $\frac{\delta^{2}}{\mathrm{k} \bar{n}^{2}}$, and the right one is $(\mathrm{k}-1) \mathrm{n}^{2}$. We will have the LKI, where the square of standard deviation over completely divided square of standard deviation is.

Thus, the new novel indicator will be:

$$
\mathrm{LKI}=\frac{\delta^{2}}{(k-1) \bar{n}^{2}}
$$

$\mathrm{k}=$ number of classes of the sample

$\bar{n}^{2}=$ diagonal average value of the sample classes,

$\delta^{2}=$ diagonal standard deviation

\section{Results}

Collaborative robotics has become one of the fastest-growing sectors of the robotics markets. If cobots is the key technology for the advancement of Industry 4.0 (Sherwani et al., 2020), it is also a burgeoning technology sector in its own right. Statzon market intelligence data utilised for this article shows that the global cobot market was already estimated to be at around $\$ 1.3$ billion in 2020, with a CAGR of almost $40 \%$ until 2028 to a total worldwide market size of $\$ 16.5$ billion. Cobots, in other words, is no longer just a niche industry but a major global industrial sector worth examining in its own right. From 2022 the market is expected to grow eightfold (Fig. 1).

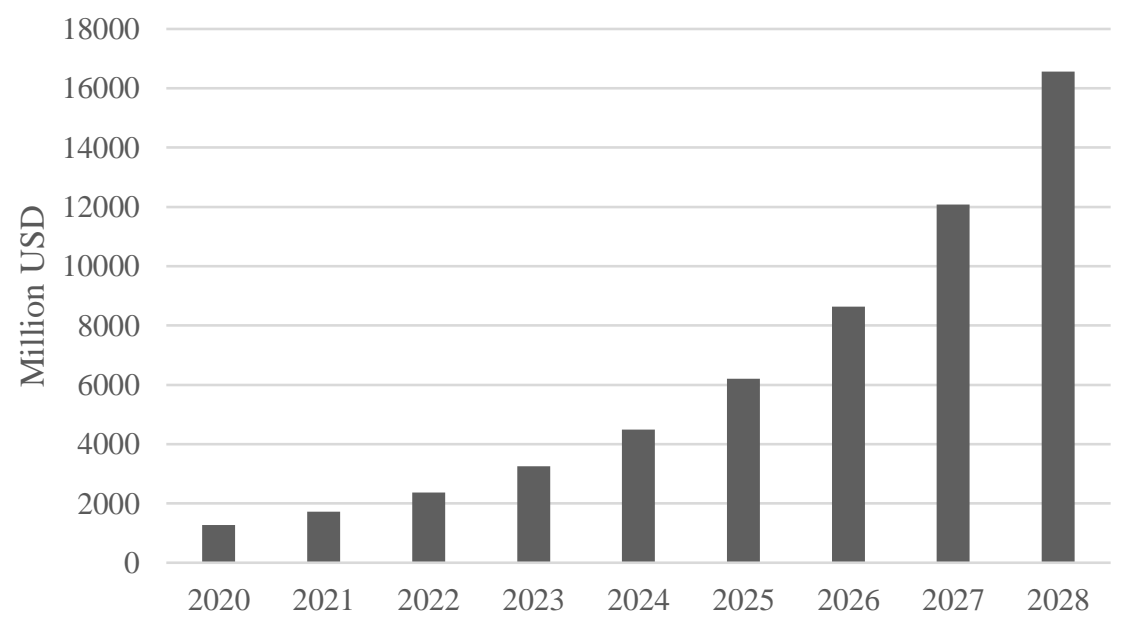

Fig. 1. Global Cobot Market Size 2020 to 2028 (Source: Statzon Ltd.)

Global Cobot Market to 2028 (Collaborative robots) represents the fast-growing industrial robotics market. Cobots currently account for around $5 \%$ of industrial robot sales. Technological advancements have made the applications of cobotics technology a reality in many manufacturing industries. 


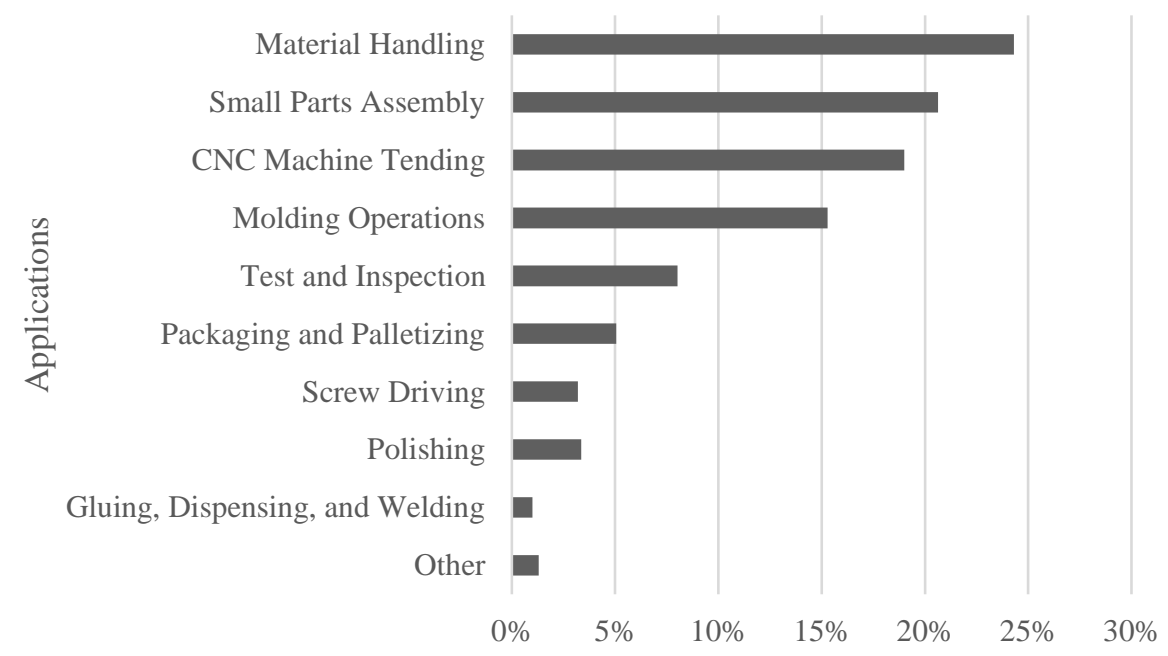

Fig.2. Applications in Global Cobot markets 2020 (Source: Statzon Ltd.)

Fig 2. shows the segments of cobot markets. The most important segments and applications in the global cobot market are Material Handling, Small Parts Assembly, CNC Machine Tending, and Molding Operations. The middle important are Test and Inspection, Packaging and Palletizing, Screw Driving and Polishing. The least important: Gluing, Dispensing, and Welding have only $1 \%$. Fig 5. reports end-user industries in global cobot markers in 2020.

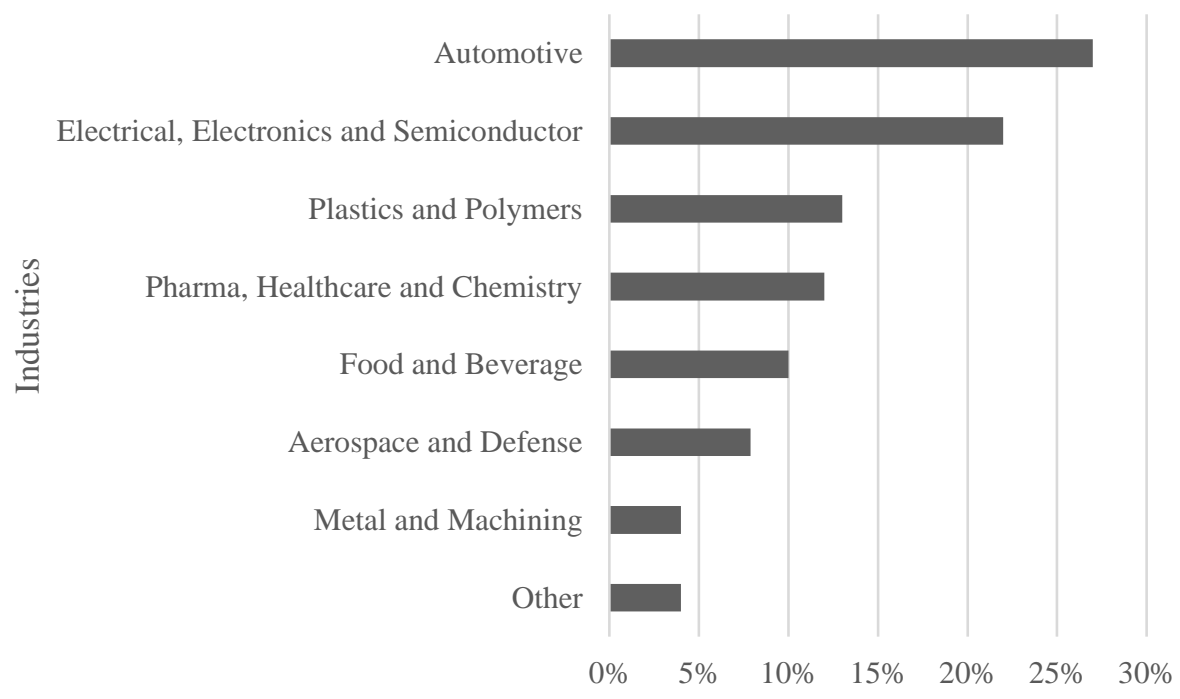

Fig. 3. The industries in Global cobot markets 2020 (Source: Statzon Ltd.)

The Cobots are used in many fields and industries. The Cobots will replace some of the traditional robots. Thus, cobots are disruptive technology and reshape the market and market structure dynamically.

Major companies in the market are Universal Robots (Denmark), Techman Robot (Taiwan), FANUC (Japan), ABB (Switzerland), Precise Automation (US), Motoman. Those are among a few emerging companies in the collaborative robot market (Statzon, Ltd. 2021). 


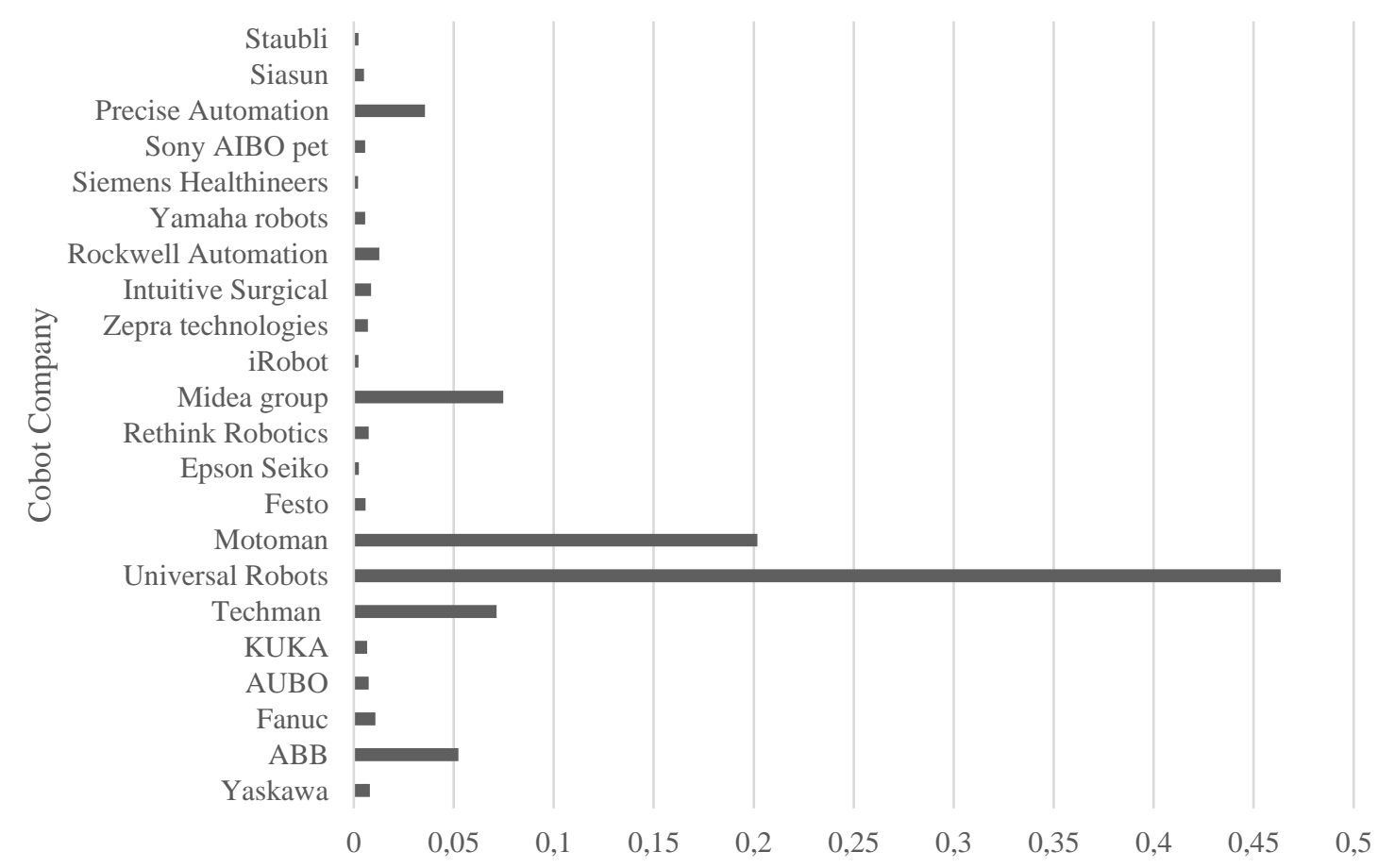

Fig. 4. Global cobot market shares in 2019 (Source: Statzon Ltd.)

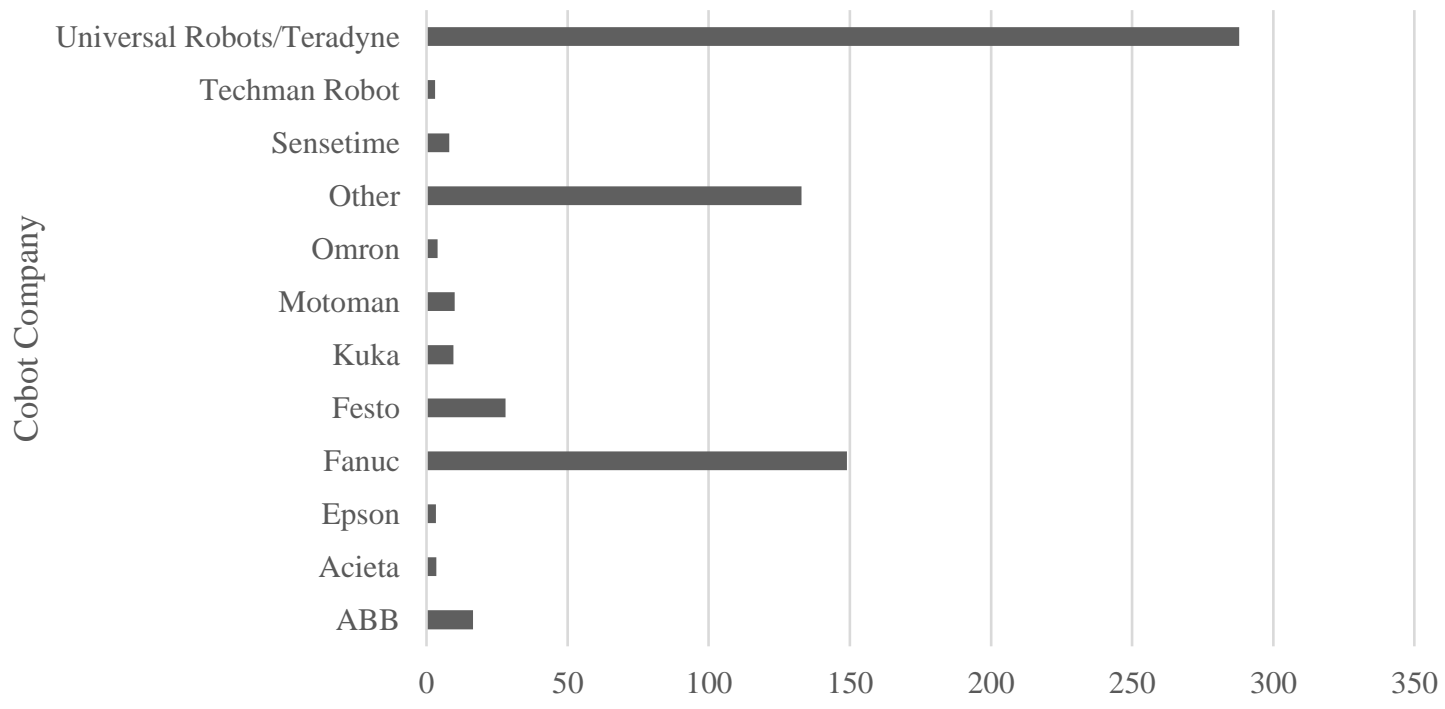

Fig. 5. Global Cobot market Shares 2020 Million USD (Source: Statzon Ltd.)

There are more than 50 cobot manufacturers globally, but only a small number of the companies have so far deployed cobots on any meaningful level of scale. The market is moderately competitive, and companies focus on innovation to remain competitive. Acquisitions and collaboration of large companies with startups are expected in the future. Universal Robots is the clear market leader with nearly half of the global market, $47 \%$ market share.

\section{Results of comparing the HHI index and the LKI index}

The following figure shows the Herfindahl-Hirschman Index (HHI) for the cobotics market 2019-2020 (the mathematic formula, HHI 1). 


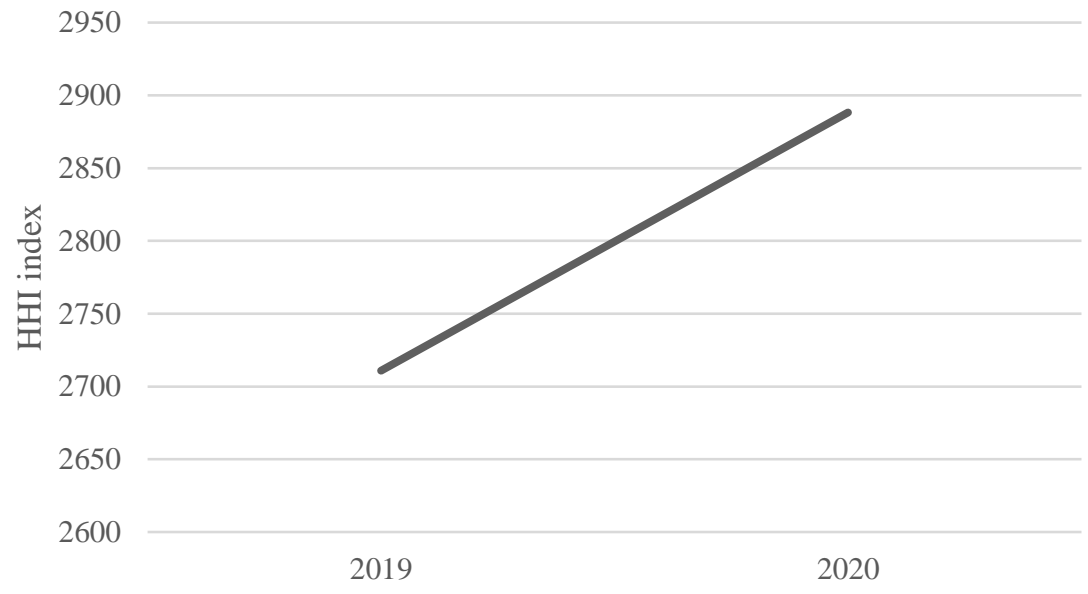

Fig. 6. The HHI indexes for Cobotics market 2019-2020 (Source: developed by the authors)

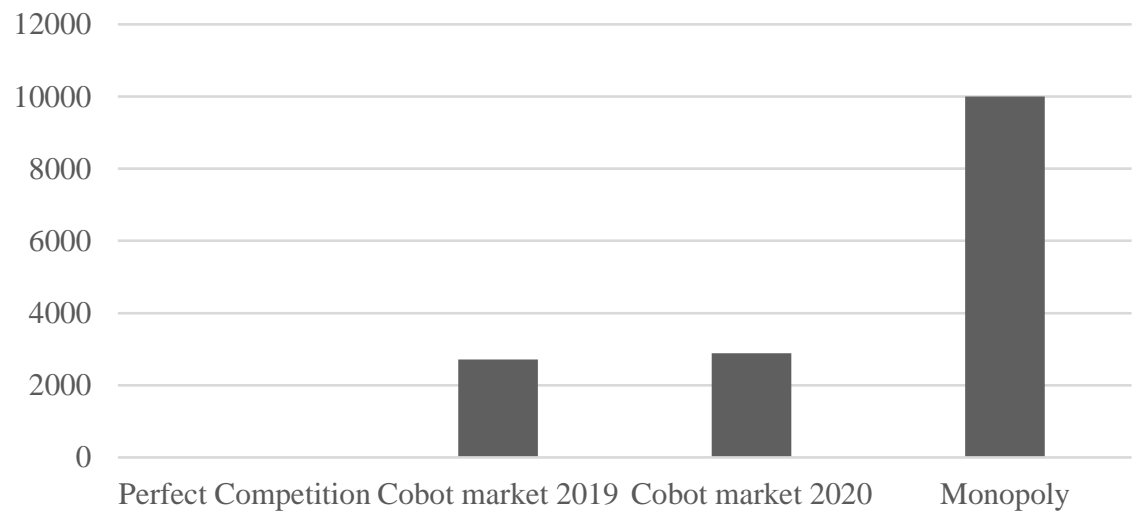

Fig. 7. The HHI analysis for global cobot market 2019-2020 compared to perfect competition and monopoly (Source: developed by the authors)

The following figure shows the new Lauraéus \& Kaivo-oja index LKI (Formula 10).

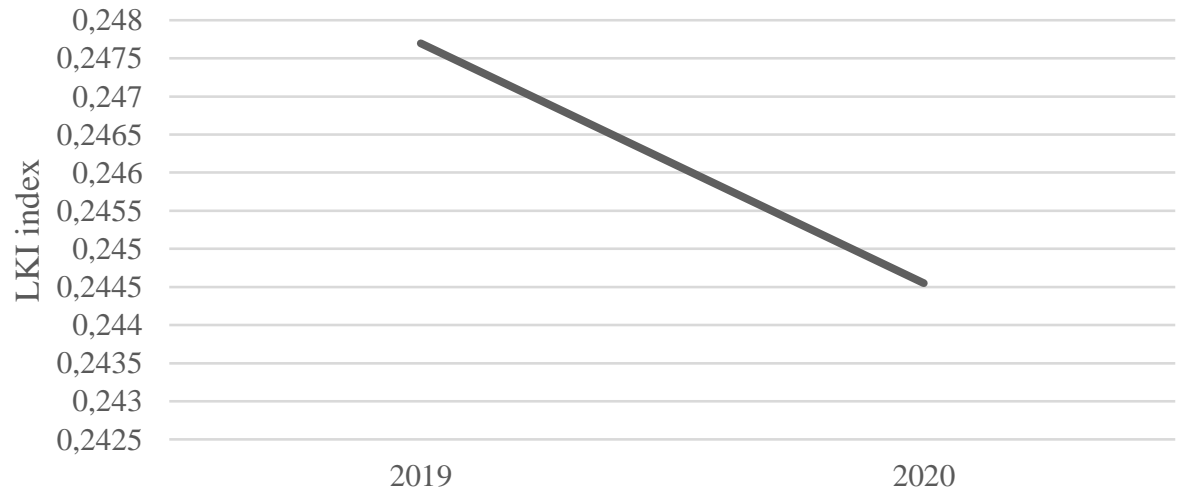

Fig. 9. Lauraéus \& Kaivo-oja Index (LKI) Global Cobot market 2019-2020 (Source: developed by the authors) 


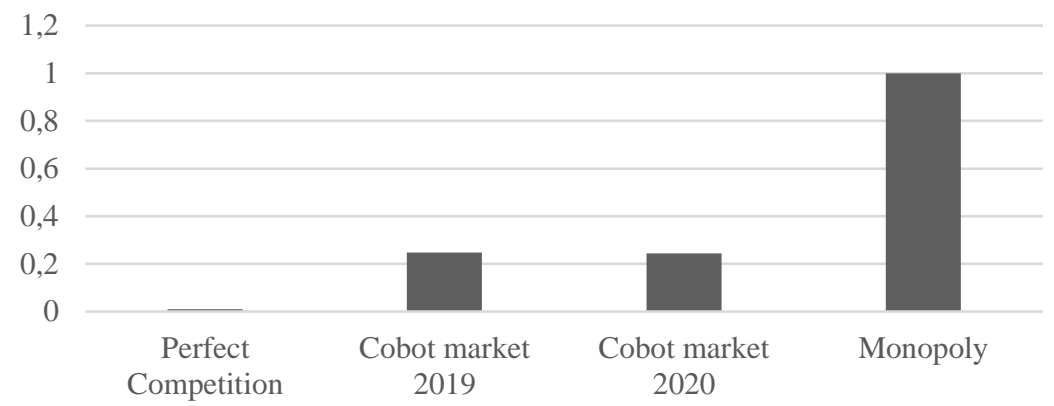

Figure 10. Lauraéus \& Kaivo-oja index (LKI) Global cobot market 2019-2020 compared to perfect competition and monopoly (Source: developed by the authors)

The paper shows results with the conventional Herfindahl-Hirschman Index alongside the novel LKI linear index.

\section{Global Cobot Market Competition Analysis}

Global cobotics markets are in an oligopoly situation at the moment. There are 1-5 bigger companies. The bigger and smaller companies are producing unique products in the different market segments.

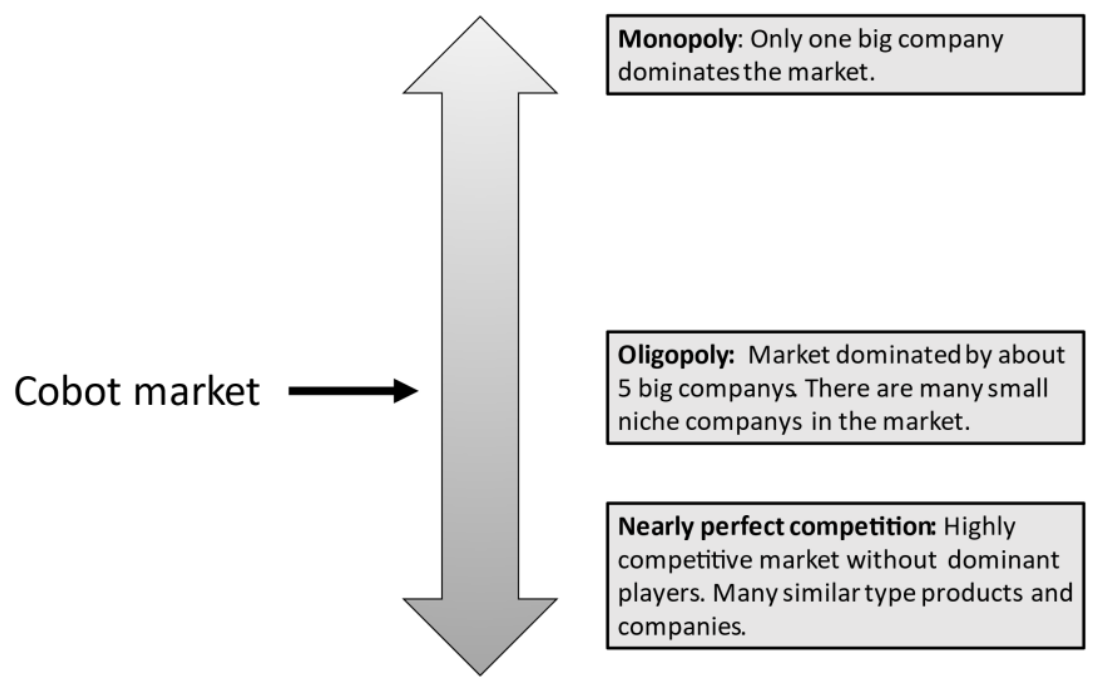

Fig. 11. Market concentration in the global cobot market (Source: developed by the authors)

There are 1-5 reasonably large companies in the cobot market. Major companies in the market are Universal Robots (Denmark), Techman Robot (Taiwan), FANUC (Japan), ABB (Switzerland), Precise Automation (US), Motoman, and Midea Group. Those are among a few emerging companies in the collaborative robot market (Statzon, Ltd. 2021). Cobots are used in many fields and by many kinds of end-users. Cobots will replace some of the traditional robots. Thus, cobots are disruptive technology and reshape the robot and cobot market and market structures.

There are a lot of small companies in the global cobot market. They produce their own special products or niche products for non-competing segments. Companies produce special products for a wide range of industries and end-users. There is a lot of niche market segments in the market that require special expertise. 


\section{Conclusions}

The Herfindahl-Hirschman Index (HHI) and the Lauraéus-Kaivo-oja Index (LKI) are statistical measures of market concentration, and they can be used to determine market competitiveness. These analyses can help various industrial stakeholders make faster decisions and better strategic plans with the easiest and fastest access to accurate, reliable, and up-to-date cobotics industry statistics, forecasts, and insights. The finding is that this study reveals the current market structure of the global cobotics market. It is a novel finding and result. Even one statistical index can summarise the nature of the trend in the marketplace.

\section{The HHI Index Concentration Ratio Gives More Weight to Larger Firms:}

The Herfindahl-Hirschman Index, concerning measures such as the concentration ratio, gives more weight to larger firms. (Rhoades 1993, Adams 2017). We think that this is not a good idea when comparing the different sizes of companies or different sizes of markets. The HHI takes into account the relative size distribution of firms in a market.

The original reason why we started to develop the $\mathrm{HHI}$ index further is that we are not able to compare the different sizes of markets and companies with the HHI index. Thus, the number of classes will distort evaluation results of the HHI index values. There are good reasons to avoid this potential statistical bias. We have presented a new index, Lauraéus-Kaivo-oja Index, to avoid biases in market analyses.

\section{The Advantages of Lauraéus-Kaivo-oja Index}

The LKI analysis approach, which we will present next in this paper, allows for separate-sized portfolio analyses of global cobots markets. The HHI increases both as the number of firms in the market decreases and the disparity in size between those firms increases. There is no statistical bias in the comparison of markets with different sizes when we present the LKI analyses. In the field market analyses, the statistical comparisons have been a hidden problem for a long time, but now this problem is solved by the LKI approach.

The size-independent analysis of global cobot market is a novel thing, which allows a broad spectrum of implications. The LKI approach allows the size of the cobot markets to be different, and the results are not dependent on the size of the sample. This is a significant advantage with respect to the conventional HHI approach. This is a fundamental methodological issue in the case of our empirical analyses.

As the well-known HHI Index, the LKI approach also helps understand the dynamics of the market structures. The LKI can be used for market, trend and competition analysis and international trade analysis. Thus, the novel LKI approach has great potential for use in these fields of market structure analyses.

The LKI $0-100 \%$ number is easier to understand than the HHI, which provides large numbers $(0-10000)$ for decision-makers to consider. In summary, the LKI percentage values are more comprehensible than the HHI values calculated with $100^{2}$. There is no calculation bias towards large companies.

\section{Different Market Situations from Perfect Competition to Monopoly, Comparing the HHI Index and LKI Indices:}

In the HHI index market share of each company is shown as a whole number. The LKI index shows the market share of each company as a decimal of the percentage value.

The HHI can have a theoretical value ranging from close to zero to 10,000 . The LKI can have a theoretical value ranging from close to 0,00 to 1,00 - the same as $0 \%-100 \%$, which we find more comprehensive.

In the HHI and the LKI market analyses I, Monopoly: The closer a market is to be a monopoly, the higher the market's concentration (and the lower its competition). If, for example, there was only one firm in an industry, that firm would have a $100 \%$ market share, and the HHI would equal 10,000, indicating a monopoly. In the same situation, the LKI would equal 1.00 , which is the same as $100 \%$, indicating a monopoly. We think that the percentage value is easier and more comprehensive to use. 
In HHI and the LKI market analyses II, Nearly perfect competition: If there were thousands of companies competing, each would have nearly a $0 \%$ market share. That means the HHI is close to zero, indicating nearly perfect competition. The LKI is 0.00 or $0 \%$ in the same situation of nearly perfect competition.

In HHI and the LKI market analyses III, Oligopoly: An oligopoly is a form of imperfect competition in which there are only a few providers of a particular service or product in the market. The oligopoly is characterised by a low level of competition and the resulting unnaturally high or low price level and a low level of production corresponding to perfect competition. In an oligopoly situation, the HHI and the LKI analyses have somewhere middle range values.

\section{Market development forecast based on the HHI and the Lauraéus-Kaivo-oja indices estimates}

Based on both the HHI and the Lauraéus-Kaivo-oja indices estimates, the market would appear to be oligopolistic dominated by a few larger firms.

Global cobot oligopolistic market: the market leader has four to five main competitors. Companies produce products for many different industries and thus do not compete with each other. There is a lot of niche markets in the market. It is expected that the market volume will increase sevenfold, and the cobots market will become more attractive and bring a lot of new small players to the market.

The HHI increases the volume of large companies and therefore shows a curve rising in a less competitive direction. The LKI takes better account of all sizes of businesses. The LKI index shows a slightly declining curve as there is a lot of small companies in the market, and the market is moving in the direction of the competitive situation of several companies.

This analysis highlights the advantage of the LKI index. Unfortunately, we did not have a longer time series for this analysis because it does not exist anywhere. Cobots are relatively new products, and this phenomenon creates a new global market. A longer time series would better present the transformation of the competitive situation and market dynamics. A longer time series would show the results better and more clearly.

\section{Future research directions}

The LKI shows a more realistic and unbiased picture and shows a better real direction of the competition situation. This shows the rationality of using this novel index. The LKI analysis does not weigh big companies and offers the right picture of market dynamics. The new index can be used for various market dynamics research. The LKI reveals market developments better. The LKI can be used for market, trend and competition analysis, international trade, export, and import analysis. We recommend using the LKI index. It is for one's free use and can be calculated with basic statistical variables.

This paper demonstrated novel and exciting possibilities of transparent index calculation tools. Realtime market structure analyses of the global cobotic industry create reliable and knowledge-based information for decision-makers and stakeholders. We hope that this kind of index will be useful in various evaluations and measurements.

\section{Acknowledgements}

The project "Platforms of Big Data Foresight (PLATBIDAFO) has received funding from European Regional Development Fund (project No 01.2.2-LMT-K-718-02-0019) under a grant agreement with the Research Council of Lithuania (LMTLT). 


\section{References}

Adams, C. (2017). What is the Herfindahl Hirschman Index (HHI) and why would you use it? Modern analyst. [Accessed 18.6.2017.] Available at:

http://www.modernanalyst.com/Careers/InterviewQuestions/tabid/128/ID/1003/What-is-the-HerfindahlHirschman-Index-HHI-and-why-would-you-use-it.aspx

Brakman, S., Garretsen, H., and van Witteloostuijn, A. (2021). Robots do not get the coronavirus: The COVID-19 pandemic and the international division of labor. Journal of International Business Studies. https://doi.org/10.1057/s41267-021-00410-9.

Economist, The (2021). Bearing fruit. After years of dithering companies are embracing automation. [Accessed 07.04.2021]. Available from Internet: https://www.economist.com/business/2021/01/16/after-years-of-ditheringcompanies-are-embracing-automation

Goldberg, K. (2019). Robots and the return to collaborative intelligence. Nature Machine Intelligence, 1, 2-4. https://doi.org/10.1038/s42256-018-0008-X

Herfindahl, O.C. (1950). National Power and the Structure of Foreign Trade. University of California. Berkley. USA.

Hirschman, A.O. (1964). The paternity of an index. American Economic Review September 1964, 54: 761-762.

Knudsen, M.S. and Kaivo-oja, J. (2020). Collaborative robots: Frontiers of current literature. Journal of Intelligent Systems: Theory and Applications, 3(2), 13-20. https://doi.org/10.1038016/jista.682479

Kopp, T., Baumgartner, M. \& Kinkel, S. (2021). Success factors for introducing industrial human-robot interaction in practice: an empirically driven framework. The International Journal of Advanced Manufacturing Technology, 112, 685-704. https://doi.org/10.1007/s00170-020-06398-0

Lauraéus T. and Kaivo-oja J., (2017). New Transparent Way to Perform Competition, Market Structure and IPR Portfolio Analyses: Analysis of the Dynamics of Trademark Competition in Finland as a Case Example, Journal of Business Management and Economics, 5 (12), December, 2017, Manuscript ID :DOI-16473163213

Kaivo-oja, J.; Lauraeus, T. (2017). Emerging trends and structural changes of global innovation ecosystems: Empirical analysis of changing patent and trademark activity of G7 countries and BRICS countries from years 1985-2015. Eurasian Academy of Sciences. Eurasian Business \& Economics Journal 11, 33-44.

Rhoades. S.A. (1993). The Herfindahl-Hirchman Index, Federal Reserve Bulletin, March 1993, 188-189.

Sherwani, F., Asad, M.M. \& Ibrahim, B.S.K.K (2020). Collaborative Robots and Industrial 4.0 (IR 4.0). 2020 International Conference on Emerging Trends in Smart Technologies (ICETST), Karachi, Pakistan, 1-5. https://doi.org/10.1109/ICETST49965.2020.9080724

Statzon Ltd. 2021 analysis www.stazon.com, [Accessed 12.4.2021].

Stieber, T. (2015) I, Cobot: Future collaboration of man and machine. The Manufacturer. 12 Nov 2015. Web: https://www.themanufacturer.com/articles/i-cobot-future-collaboration-of-man-and-machine/ 